\title{
AVALIAÇÃO DE DADOS DE PRECIPITAÇÃO PARA O MONITORAMENTO DO PADRÃO ESPAÇO-TEMPORAL DA SECA NO NORDESTE DO BRASIL
}

SANTOS, Sergio Rodrigo Quadros dos - sergiorofrigoquadros@gmail.com Centro Nacional de Monitoramento e Alertas de Desastres Naturais / CEMADEN

CUNHA, Ana Paula Martins do Amaral - ana.cunha@cemaden.gov.br Centro Nacional de Monitoramento e Alertas de Desastres Naturais / CEMADEN

RIBEIRO-NETO, Germano Gondim - germanogn@hotmail.com

Centro Nacional de Monitoramento e Alertas de Desastres Naturais / CEMADEN

RESUMO: Um importante fator intrínseco da região Nordeste do Brasil (NEB) é sua variabilidade climática natural. A caracterização da variabilidade espaçotemporal da chuva nesta região torna-se importante no contexto da gestão do risco de seca, seja para subsidiar a tomada de decisões em relação às tendências climáticas, como para o monitoramento de eventos extremos de precipitação em curto e médio prazo. No entanto, a falta de conjuntos de dados observacionais de precipitação de longo prazo e concomitantemente consistentes, são os grandes obstáculos para o estudo e o monitoramento do padrão espaço-temporal da chuva. Posto isto, o objetivo do presente estudo foi avaliar o desempenho espaço-temporal de duas diferentes fontes de dados de precipitação (dados observacionais interpolados e obtidos por sensoriamento remoto) com a finalidade de criar um banco de dados conciso para a caracterização e o monitoramento da seca no NEB. De modo geral, o padrão sazonal de precipitação no NEB foi bem representado tanto por meio dos dados observacionais interpolados (dados oriundos do CPTEC/INPE) como pelos dados obtidos por sensoriamento remoto (CHIRPS). As análises quantitativas evidenciaram também que o CHIRPS apresenta erros sistemáticos de subestimativa e superestimava, porém, os valores de RMSE não ultrapassam 5 $\mathrm{mm}$ por estação do ano. Dessa maneira, foi possível a criação de uma nova série temporal de precipitação que compreende o período 1988 a 2017. O SPI calculado considerando o novo conjunto de dados de precipitação (CHIRPSCPTEC/INPE) representou de maneira acurada os eventos secos e chuvosos no NEB quando comparados com aqueles identificados apenas com o uso do CHIRPS. Tal resultado corrobora a utilização da nova série climatológica no monitoramento de eventos extremos na região, principalmente os eventos de seca, uma vez que, são recorrentes e persistentes, permitindo assim uma melhor avaliação dos seus impactos na região.

Palavras-chave: Monitoramento da seca, CHIRPS, SPI, Semiárido

PRECIPITATION DATASET FOR THE MONITORING OF THE SPATIAL-TEMPORAL PATTERN OF DROUGHT IN THE BRAZILIAN NORTHEAST

ABSTRACT: An important intrinsic factor in the Brazilian Northeast (NEB) is its natural climatic variability. The characterization of the spatial-temporal variability of precipitation in this region becomes important in the context of drought risk management, either to subsidize decision-making regarding climate trends, or to monitor extreme precipitation events deadline. However, the lack of observational long-term and concurrently consistent observational datasets are major obstacles to the study and monitoring of the rainfall spatial-temporal pattern. Therefore, the goal of this study was to evaluate the spatio-temporal performance from two different sources of precipitation data 
(observational data interpolated and obtained by remote sensing) in order to create a concise database for the characterization and drought monitoring in the NEB. In general, the seasonal pattern of precipitation in NEB was well represented by both interpolated observational data (CPTEC / INPE data) and remote sensing data (CHIRPS). The quantitative analysis also showed that CHIRPS presents systematic errors of underestimation and overestimation, but RMSE values do not exceed $5 \mathrm{~mm}$. Thus, it was possible to create a new time series of precipitation that covers the period 1988 to 2017. The SPI calculated considering the new precipitation dataset (CHIRPS-CPTEC / INPE) has accurately represented the dry and rainy events in the NEB when compared to those identified only with the use of CHIRPS. This result corroborates the use of the new climatological series in the monitoring of extreme events in the region, especially the drought events, since they are recurrent and persistent, allowing a better evaluation of their impacts in the region.

Keywords: Drought Monitoring, CHIRPS, SPI, Semiarid

EVALUACIÓN DE DATOS DE PRECIPITACIÓN PARA EL MONITOREO DEL PATRÓN ESPACIO-TEMPORAL DE LA SEQUÍA EN EL NORDESTE DE BRASIL

RESUMEN: Un importante factor intrínseco de la región Nordeste de Brasil (NEB) es su variabilidad climática natural. La caracterización de la variabilidad espacio-temporal de la lluvia en esta región se vuelve importante en el contexto de la gestión del riesgo de sequía, ya sea para subsidiar la toma de decisiones en relación a las tendencias climáticas, como para el monitoreo de eventos extremos de precipitación en corto y medio plazo. Sin embargo, la falta de conjuntos de datos observacionales de precipitación a largo plazo y concomitantemente consistentes, son los grandes obstáculos para el estudio y el monitoreo del patrón espacio-temporal de la lluvia. El objetivo del presente estudio fue evaluar el desempeño espacio-temporal de dos diferentes fuentes de datos de precipitación (datos observacionales interpolados y obtenidos por sensoriamiento remoto) con la finalidad de crear un banco de datos conciso para la caracterización y el monitoreo de la situación seca en el NEB. En general, el patrón estacional de precipitación en el NEB fue bien representado tanto por medio de los datos observacionales interpolados (datos provenientes del CPTEC / INPE) como por los datos obtenidos por sensoriamiento remoto (CHIRPS). Los análisis cuantitativos evidenciaron también que el CHIRPS presenta errores sistemáticos de subestimativa y sobreestimaba, sin embargo, los valores de RMSE no superan los $5 \mathrm{~mm}$ por estación del año. De esta manera, fue posible la creación de una nueva serie temporal de precipitación que comprende el período 1988 a 2017. El SPI calculado considerando el nuevo conjunto de datos de precipitación (CHIRPS-CPTEC / INPE) representó de manera acurada los eventos secos y lluviosos NEB cuando se comparan con aquellos identificados sólo con el uso del CHIRPS. Este resultado corrobora la utilización de la nueva serie climatológica en el monitoreo de eventos extremos en la región, principalmente los eventos de sequía, ya que son recurrentes y persistentes, permitiendo así una mejor evaluación de sus impactos en la región.

Palabras Clave: Monitoreo de sequías, CHIRPS, SPI, semiárido

\section{INTRODUÇÃO}

A região Nordeste do Brasil (NEB) é uma das mais problemáticas no que se refere à disponibilidade hídrica. Um importante fator intrínseco da região é a grande variabilidade climática natural (HASTENRATH, 1984; MAGALHÃES e GLANTZ, 1992; FERREIRA et al. 2018). A variabilidade no regime de chuvas no NEB ocorre em virtude da atuação de sistemas atmosféricos em diferentes escala de tempo e espaço, por exemplo, a Zona de Convergência Intertropical (ZCIT), os vórtices Ciclônicos de Altos Níveis (VCAN), os Sistemas Frontais (SF), os distúrbios Ondulatórios de Leste (DOLs), a convecção organizada em forma de linhas de instabilidade, aglomerados convectivos e a Zona de Convergência do Atlântico Sul (ZCAS) (UVO e NOBRE, 1989; MOLION E BERNADO, 2002; 
COUTINHO et al. 2010; REBOITA et al. 2010; COSTA, 2010; NÓBREGA e SANTIAGO, 2014; ASSIS et al. 2015). O ENSO (El Niño Oscilação Sul) tem grande influência sobre esses sistemas produtores de chuva já que afetam o posicionamento longitudinal dos ramos ascendentes e descendentes da Célula de Walker. Na fase quente (El Niño), seu ramo ascendente principal se posiciona sobre as águas aquecidas do Pacífico e causa subsidência e alta pressão sobre o Norte da América do Sul, deslocando a ZCIT mais ao norte e os SF e ZCAS mais ao sul, o que provoca secas severas na Região. Já os eventos em sua fase fria (La Niña), parecem estar associados á intensificação dos ramos ascendentes da Célula de Walker sobre os continentes, aumentando os totais pluviais. Durante os eventos de La Niña, os ventos alísios se tornam mais intensos, resultando na intensificação da ressurgência das águas do Pacífico. Essas alterações contribuem para a maior concentração de águas quentes a oeste do Pacífico e com isso a intensificação da célula de circulação de Walker (HASTENRATH e HELLER, 1977; HASTENRATH, 1984; MOURA e SHUKLA, 1981, NOBRE e MELO, 2001).

A variabilidade de chuvas no NEB também é influenciada pela TSM do Atlântico tropical. O padrão (dipolo de TSMs) de anomalias positivas (negativas) de TSM no Atlântico Sul e anomalias negativas (positivas) no Atlântico Norte também se associa com anos chuvosos (secos) no NEB (HASTENRATH e HELLER, 1977).

Além da variabilidade climática natural, o NEB também é constituído por várias sub-regiões, onde predomina uma grande diversificação de vegetação, relevo, solo, água e de aspectos socioeconômicos. O relevo da região interfere diretamente na circulação das massas de ar e atua como barreira para o transporte de umidade para o interior do semiárido (COSTA, 2012). Cerca de $50 \%$ do NEB apresenta clima do tipo semiárido, com média anual de precipitação inferior a $800 \mathrm{~mm}$, sendo esta, inferior ao potencial de evapotranspiração da região. A região semiárida é ainda caracterizada pela recorrência de eventos de secas. As secas são um fenômeno natural, uma alteração do regime hidrometeorológico, que afetam principalmente os mais vulneráveis da região, criando situações de deficiência hídrica e riscos para a segurança alimentar e energética na região (EAKIN et al. 2014, MARENGO et al. 2017).

Em adição, a agricultura de subsistência e a pecuária extensiva praticadas na região semiárida são variáveis consideradas de alto risco, devido principalmente à alta variabilidade espacial e temporal da chuva. As projeções futuras de clima indicam riscos de secas intensas no semiárido, reduções de chuva em até $40 \%$ e aumento de dias secos consecutivos. Além disso, o aumento da frequência e intensidade dos anos com a fase positiva do ENSO (EI Niño Oscilação Sul) causados pelas mudanças climáticas podem também aumentar a escassez hídrica e o risco de secas (ALVES e REPELLI, 1992, MARENGO, 2008). Os impactos dessas alterações poderão afetar diretamente cerca de 7 milhões de pessoas que são vinculadas à agricultura familiar no NEB, e que frequentemente se encontram em condições de extrema pobreza (IBGE, 2006; LINDOSO et al., 2011).

Sendo assim, o conhecimento da variabilidade espaço-temporal da precipitação nesta região torna-se importante no contexto da gestão do risco de seca, seja para subsidiar a tomada de decisões em relação às tendências climáticas, como para o monitoramento de eventos extremos de precipitação em 
curto e médio prazo. No entanto, a falta de conjuntos de dados observacionais de precipitação de longo prazo e concomitantemente consistentes, são os grandes obstáculos para o estudo e o monitoramento do padrão de chuva na região. Além disso, as incertezas sobre as medidas observacionais afetam diretamente avaliação dos dados de precipitação (MARENGO, 2012). Exemplos de conjunto de dados que podem ser utilizados no estudo da variabilidade espaço-temporal da precipitação de uma região extensa como o NEB, incluem: i) dados de estações meteorológicas interpolados para grades regulares, ii) dados de precipitação obtidos por sensoriamento remoto e iii) dados de precipitação oriundos de simulação numérica por meio de modelos de previsão de tempo ou de clima (FASULLO, 2012: LIMBERGER e SILVA, 2018).

Diversos métodos e índices têm sido desenvolvidos para a avaliação e quantificação da seca, considerando diferentes variáveis de causa e resposta da seca, tais como precipitação, umidade do solo, evapotranspiração, condição da vegetação, entre outros (PALMER, 1965, 1968; GIBBS \& MAHER, 1967; SHAFER \& DEZMAN, 1982; KOGAN, 1990, 2002; MCKEE et al.,1993; KEYANTASH \& DRACUP, 2004, BHUIYAN et al., 2006, ABBAS et al., 2014). Dentre os índices mais comuns utilizados no monitoramento de secas e que considera apenas dados de precipitação, destaca-se o Índice Normalizado de Precipitação (SPI, sigla em inglês), desenvolvido por Mckee et al. (1993, 1995). O SPI baseia-se na distribuição de probabilidades da precipitação e pode ser calculado em diferentes escalas de tempo, viabilizando o uso do índice na avaliação da disponibilidade hídrica seja de curta ou longa duração (HAYES et al., 1999). Além disso, por se tratar de um índice normalizado, permite a comparação do índice entre diferentes locais e climas. No entanto, para o cálculo do SPI é necessário dispor de um período continuo de pelo menos 30 anos de dados de precipitação (MCKEE et al.,1993), o que muitas vezes inviabiliza a obtenção do índice com maior resolução espacial para uma região. Nesse contexto, o objetivo do presente estudo é avaliar o desempenho de duas diferentes fontes de dados de precipitação, sendo a primeira oriunda de dados observacionais interpolados (CPTEC/INPE) e a segunda de dados obtidos por sensoriamento remoto (CHIRPS). A finalidade dessa avaliação é obter um banco de dados conciso e com resolução espaço-temporal satisfatória para a caracterização e o monitoramento de eventos de seca no NEB.

\section{MATERIAL E MÉTODOS}

\section{1 ÁREA DE ESTUDO}

A Região do NEB ocupa uma área de 1,56 milhões de km2 e abrange um total de 1793 municípios com uma população de aproximadamente 52 milhões de habitantes (Figura 1). A região semiárida inserida no limite do NEB (SANEB), possui uma área de aproximadamente 1 milhão de $\mathrm{km} 2$, segundo a nova delimitação publicada pela SUDENE (SUDENE, 2018). O SANEB é marcado pela recorrência de eventos de seca e compreende a população mais pobre do país, portanto a região mais vulnerável aos efeitos da seca. Nos últimos seis anos (2012-2017), a região vem sendo intensamente impactada por um processo prolongado de seca, já definido como o "evento" mais intenso dos últimos 30 anos (BRITO et al., 2017; MARENGO et al., 2017, CUNHA et al., 2018). 


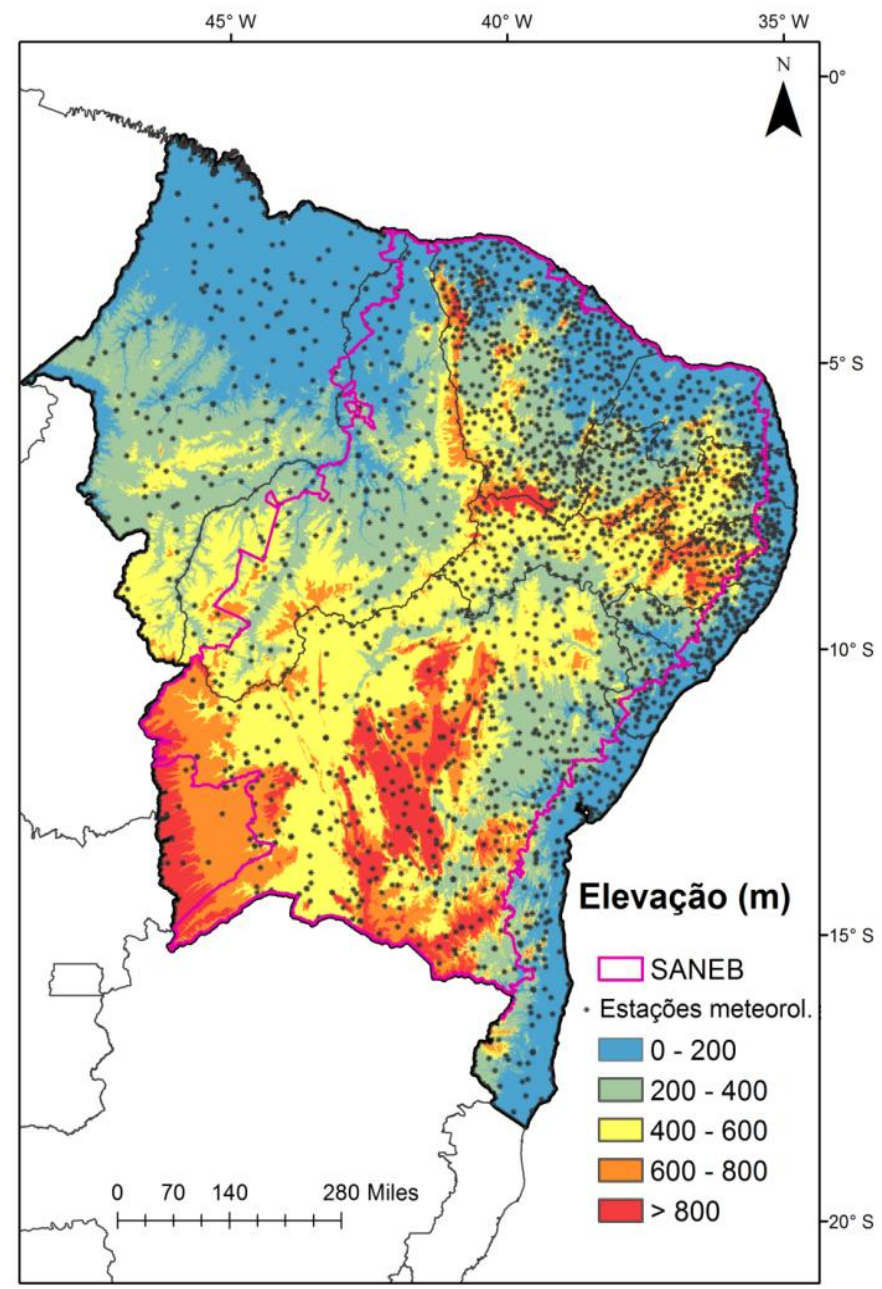

Figura 1 - Região Nordeste do Brasil com a nova delimitação do semiárido do Nordeste (SANEB-SUDENE, 2018); Localização das estações meteorológicas utilizadas do CPETC/INPE.

\subsection{DADOS DE PRECIPITAÇÃO}

Os dois conjuntos de precipitação mensal avaliados no presente estudo compreendem ao período de 1999 a 2017:

A precipitação estimada pelo Climate Hazards Group InfraRed Precipitation with Stations (CHIRPS), consiste em uma série de dados de precipitação em grade de $0,5^{\circ}$. De acordo com Funk et al. (2014) a assimilação dos dados de estação no CHIRPS inclui um algoritmo para minimizar a influência de falsos zeros e de observações erradas. Os dados do CHIRPS compreendem o período de 1981 até 2018 e são disponibilizados em http://chg.geog.ucsb.edu/data/chirps/.

Os Dados interpolados de precipitação considerados no presente estudo são provenientes do Centro de Previsão de Tempo e Estudos Climáticos (CPTEC/INPE, 2018) e consiste de dados observados de estações meteorológicas 
de diversas fontes tais como, do Instituto Nacional de Meteorologia (INMET), do Centro Nacional de Monitoramento e Alertas de Desastres Naturais (Cemaden) e de Centros Estaduais de Meteorologia. No total, foram considerados dados de 1938 pluviômetros espalhados por todo o Nordeste (Figura 1). Estes dados são processados e interpolados pelo CPTEC/INPE desde o ano de 1998 no âmbito do projeto PROCLIMA/CPTEC (SOUZA et al., 2001). Os dados são interpolados em grade regular de $5 \mathrm{~km}$ utilizando a técnica de kriging (MATHERON, 1969).

Com a finalidade de se avaliar o padrão espaço-temporal da precipitação, foram calculadas as médias sazonais de precipitação de cada conjunto de dados, assim como, as métricas estatísticas Viés, RMSE e correlação. Para as análises estatísticas, os dados de chuva do CPTEC/INPE são considerados como referência.

Considerando que a base de dados interpolados de precipitação do CPTEC para a Região Nordeste, com resolução de $5 \mathrm{~km}$, tem o inicio apenas a partir do ano de 1999, e, portanto não compreende um conjunto de 30 anos de dados, após a avaliação dos bancos de dados, foi criada uma série de precipitação mensal utilizando os dados do CHIRPS e CPTEC/INPE. Para isso, os dados do CHIRPS do período de 1988 a 1998 foram utilizados para completar a série temporal de dados do CPTEC.

\subsection{DADOS ATMOSFÉRICOS E OCEÂNICOS}

Com a finalidade de realizar a caracterização das condições médias e anômalas do sistema oceano-atmosfera e associá-las ao padrão espaçotemporal da precipitação na região Nordeste, foram utilizados dados globais atmosféricos e oceânicos de reanálise. As variáveis analisadas foram as componentes do vento meridional e zonal, o movimento vertical e a temperatura da superfície do mar (TSM). Esses dados foram adquiridos no National Centers for Environmental Prediction / National Center for Atmospheric Research (NCEP / NCAR). Eles estão dispostos em uma grade regular com uma resolução espacial de $2.5^{\circ}$ de latitude $\times 2.5^{\circ}$ de longitude e cobrem o período de 1988 a 2017.

Foram elaborados mapas com a distribuição horizontal das anomalias de TSM e seções retas verticais para ilustrar a circulação anômala zonal e meridional. Na seção reta vertical zonal foram utilizadas as anomalias da componente zonal do vento e do movimento vertical, sendo representada a média calculada para a faixa latitudinal de $16^{\circ} \mathrm{S}$ a $3^{\circ} \mathrm{S}$, de forma que a latitude de $8^{\circ} \mathrm{S}$ está no ponto médio da faixa. Analogamente, foi selecionada a faixa longitudinal de $47^{\circ} \mathrm{W}$ a $38^{\circ} \mathrm{W}$ para obtenção das médias das anomalias da componente meridional do vento e do movimento vertical representadas nas seções retas verticais meridionais. Esse tipo de representação possibilita diagnosticar áreas com movimentos verticais anômalos na atmosfera.

\subsection{MÉTRICAS ESTATÍSTICAS}

\subsubsection{VIÉS}

O viés ou bias (Equação 1), como encontrado frequentemente na literatura, é uma metodologia estatística utilizada para expressar o erro sistemático ou tendenciosidade no prognóstico de determinada variável (WILKS, 
2006). O viés negativo indica subestimativa do parâmetro avaliado e quanto mais negativo, maior é o erro de subestimativa. Por outro lado, quanto mais positivo for o viés, a superestimava do parâmetro será maior. Já quando o viés se aproximar do zero, o parâmetro está sendo bem representado, indicando que o valor estimado se aproxima do valor observado.

$$
\text { Vies }=s-o
$$

Onde " $s$ " representa o dado de estimativa e " $o$ " representa o dado controle.

\subsubsection{RAIZ DO ERRO QUADRÁTICO MÉDIO}

Uma medida frequentemente usada na verificação da acurácia de dados estimados é a Raiz do Erro Quadrático Médio (RMSE), como descrito em Wilks (2006). O RMSE mostra a amplitude do erro, ele é sempre positivo. RMSE =0 indica estimativa perfeita. O RMSE é definido por:

$$
\text { RMSE: } \sqrt{\frac{1}{n}} \sum_{i=1}^{n}(s-o)^{2}
$$

As variáveis na expressão acima são as mesmas da equação 1 .

\subsubsection{COEFICIENTE DE CORRELAÇÃO}

O coeficiente de correlação ( $r$ ) é uma medida da intensidade ou grau de associação entre duas variáveis analisadas, neste caso, a precipitação do CPTEC e CHIRPS. Este índice não é sensível ao viés que, eventualmente, podem estar presentes nas estimativas de chuva (WILKS, 2006). Pode ser calculado pela seguinte expressão:

$$
\mathrm{R}: \frac{\sum_{i=1}^{n}(S i-\bar{S})(O i-\bar{O})}{\sqrt{\sum_{i=1}^{n}(S i-\bar{S})^{2}(O i-\bar{O})^{2}}}
$$

As variáveis na expressão acima são as mesmas da equação 1 .

\section{5 ÍNDICE DE PRECIPITAÇÃO NORMALIZADA}

Os dados de precipitação foram posteriormente utilizados para o cálculo do Índice de Precipitação Normalizada (SPI). O SPI é utilizado para a identificação e quantificação dos eventos secos e chuvosos sobre o NEB. A versatilidade deste índice está na simplicidade do seu cálculo, além disso, ele identifica eventos secos e chuvosos em diferentes escalas de tempo $(3,6,12$ meses, etc), o que permite monitorar a dinâmica temporal desses eventos, isto é, o desenvolvimento e declínio. Como é um índice padronizado a classificação das categorias de seca/chuva pode ser utilizada em qualquer região do globo (HAYES, 2000; SANTOS et al. 2017). Adicionalmente, O SPI apresenta uma vantagem em relação aos demais índices, por exemplo, Índice de Severidade de Seca de Palmer (PDSI), pois utiliza apenas dados mensais de precipitação, ou seja, não se faz necessário a utilização de outras variáveis meteorológicas na detecção dos eventos secos e chuvosos (GUTTMAN, 1998). Por fim, este índice é 
muito recomendado pela World Meteorological Organization (WMO, 2009) para os estudos relacionados a eventos secos e chuvoso.

Conceitualmente, o SPI é simplesmente a variável reduzida $\mathrm{Zi}$ da distribuição normal da precipitação:

$$
\mathrm{SPI}=z_{i}=\left(\frac{P_{i}-\bar{P}}{\sigma_{i}}\right)
$$

na qual i é a escala de tempo (1, 3, 6, 12 meses); Pi a precipitação observada ; e бi, são respectivamente, a média e o desvio padrão da série ajustada.

Detalhes sobre o cálculo SPI pode ser encontrado em vários trabalhos, incluindo McKee et al. (1993), Guttman (1998), Hosseini-Moghari e Araghinejad, (2015) e Dos Santos et al. 2017. Os valores de SPI foram classificados de acordo com McKee et al. (1993) (Tabela 1). Além disso, neste estudo foram selecionadas as escala de tempo 3, 6 e 12 meses. De acordo com Dos Santos et al. (2017) o SPI trimestral (SPI-3) reflete as condições de curto prazo, é importante para monitoramento das precipitações sazonais. A escala semestral do SPI (SPI-6) representa os eventos de média duração, úteis para o monitoramento do período de transição entre estação seca e a chuvosa. O SPI anual (SPI-12) reflete padrões de precipitação de longo prazo. É utilizado para monitorar a variabilidade anual e interanual.

Tabela 1 - Classificação dos períodos secos e chuvosos do SPI segundo McKee et al., (1993)

\begin{tabular}{cc}
\hline Valores de SPI & Classes \\
\hline$<-2,0$ & Seca Extrema \\
$-1,99$ a $-1,50$ & Seca Severa \\
$-1,49$ a $-1,0$ & Seca Moderada \\
$-0,99$ a $-0,49$ & Seca Fraca \\
$-0,49$ a 0,49 & Quase Normal \\
0,49 a 0,99 & Chuva Fraca \\
0,99 a 1,49 & Chuva Moderada \\
1,49 a 1,99 & Chuva Severa \\
$>2,0$ & Chuva Extrema \\
\hline
\end{tabular}

\section{RESULTADOS}

\subsection{VARIABILIDADE SAZONAL DA PRECIPITAÇÃO.}

A Figura 2 mostra os mapas sazonais da precipitação observada (CPTEC/INPE) e estimada por satélite (CHIRPS) sobre o NEB, correspondentes à média do período de 1999 a 2017. Durante o verão e o outono, os maiores acumulados de precipitação são observados principalmente na porção norte da região, a qual inclui os estados do Maranhão, Piauí, norte e sul do Ceará e os interiores da Paraíba e Rio Grande do Norte. Nestas estações, o norte do NEB sofre influências diretas da ZCIT, que se desloca mais ao sul, e dos vórtices ciclônicos. Além disso, outros fatores tais como brisas marítimas e linhas de instabilidade podem afetar o volume pluviométrico nessa região (GAN e KOUSKY, 1986; COUTINHO et al. 2010; LIMA et al. 2010; REBOITA et al. 2010). 
No inverno, a precipitação é concentrada no litoral leste do NEB (Zona da Mata), onde é observado acumulados de precipitação superiores a $100 \mathrm{~mm}$. Nessa região, as precipitações ocorrem por meio da influência ocasionada pelas massas de ar tropical ou ainda por meio dos distúrbios ondulatórios de leste que atingem o litoral nordestino com maior intensidade (MOLION e BERNADO, 2002; MENDONÇA e DANNI-OLIVEIRA, 2007; MACHADO et al. 2012; SANTOS et al. 2016a; SANTOS et al. 2016b).

Na primavera, as porções sul e oeste do Nordeste (sul e oeste da Bahia, sul do Maranhão e Piauí), apresentam acumulados de precipitação superiores à $160 \mathrm{~mm}$, tendo como os principiais mecanismos produtores de chuva os sistemas pré-frontais, convecção local e ZCAS (MOLION e BERNARDO, 2002; REBOITA et al. 2010).

De modo geral, os resultados apresentados corroboram com aqueles encontrados por Kousky (1979) e Cavalcanti (2009), onde foram identificados três regimes de precipitação no NEB. Em termos qualitativos, para todas as estações do ano, o padrão espacial climatológico da precipitação é bem representado nas estimativas do CHIRPS, apesar de algumas regiões apresentarem discrepâncias (para mais ou para menos) nos valores de precipitação estimada.
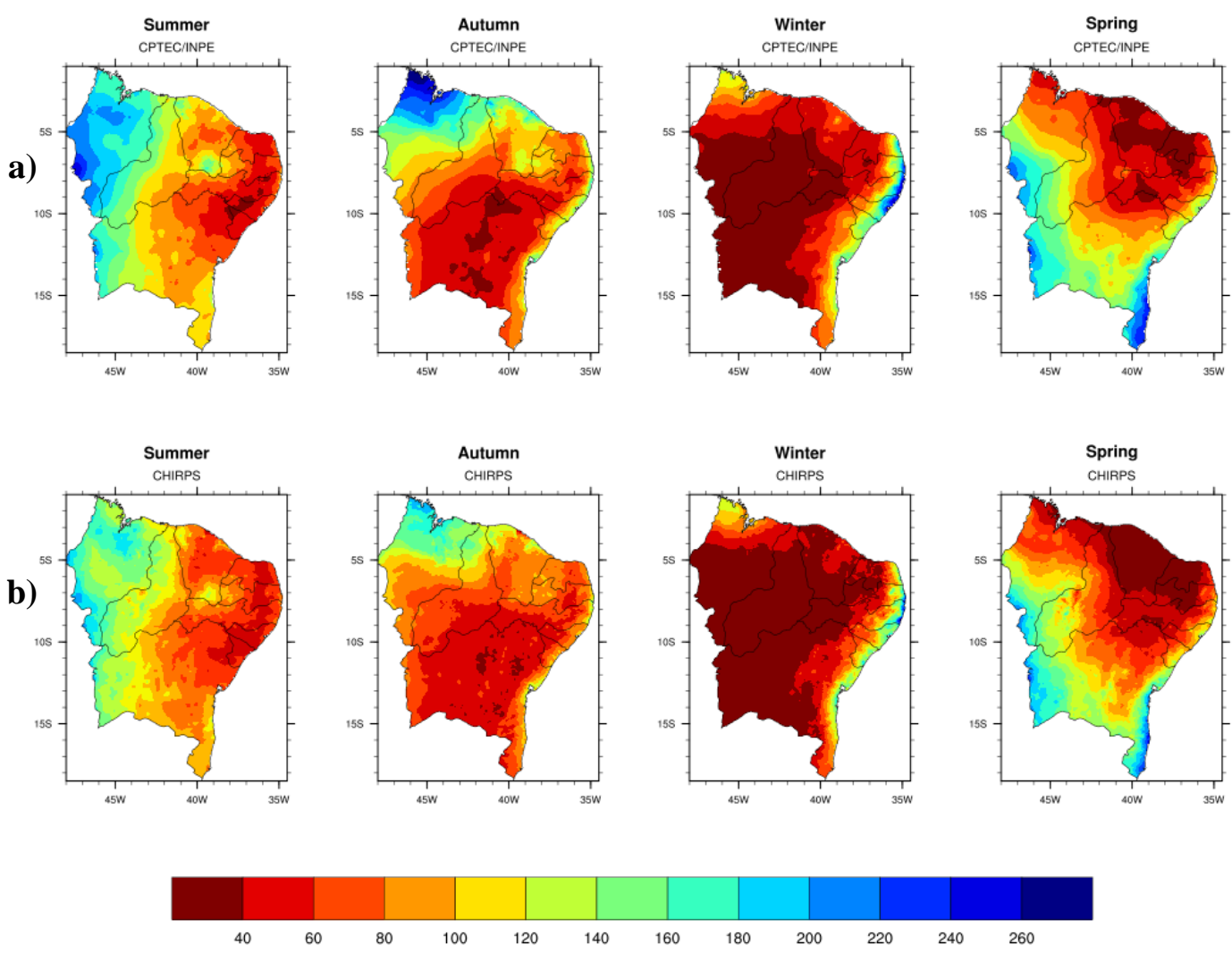

Figura 2 - Precipitação sazonal (mm) do CPTEC/INPE (a) e CHIRPS (b) para as quatro estações do ano, média no período de 1999 a 2017.

A análise quantitativa, isto é, a diferença da intensidade entre o estimado e o observado, foi realizada com base nos coeficientes estatísticos viés e RMSE. Na Figura 3a são mostrados os valores de viés para as quatro estações do ano. 
Nota-se que, durante o verão e outono há um contraste mais acentuado entre valores positivos e negativos de viés $(-50 \mathrm{~mm}$ a $50 \mathrm{~mm})$ no $\mathrm{NEB}$, e nas estações de inverno e primavera nota-se a predominância de viés seco (valores positivos). O viés entre -5 e $5 \mathrm{~mm}$ observado nas quatro estações indica que o CHIRPS foi capaz de representar a precipitação na Região.

Para o RMSE nas quatros estações do ano (Figura 3b), os maiores valores observados foram no verão e outono com valores variando entre 3 a $5 \mathrm{~mm}$ em toda a Região, o que pode indicar uma maior deficiência na estimativa da chuva nessas estações pelo CHIRPS. No inverno, os maiores valores de erro se concentram no litoral do NEB, e por sua vez a, primavera apresenta os menores valores de erro variando entre 0,5 a $3 \mathrm{~mm}$. Em adição, os valores de RMSE indicam a ocorrência de erros sistemáticos do CHIRPS relacionados a superestimava/subestimativa abordados anteriormente.
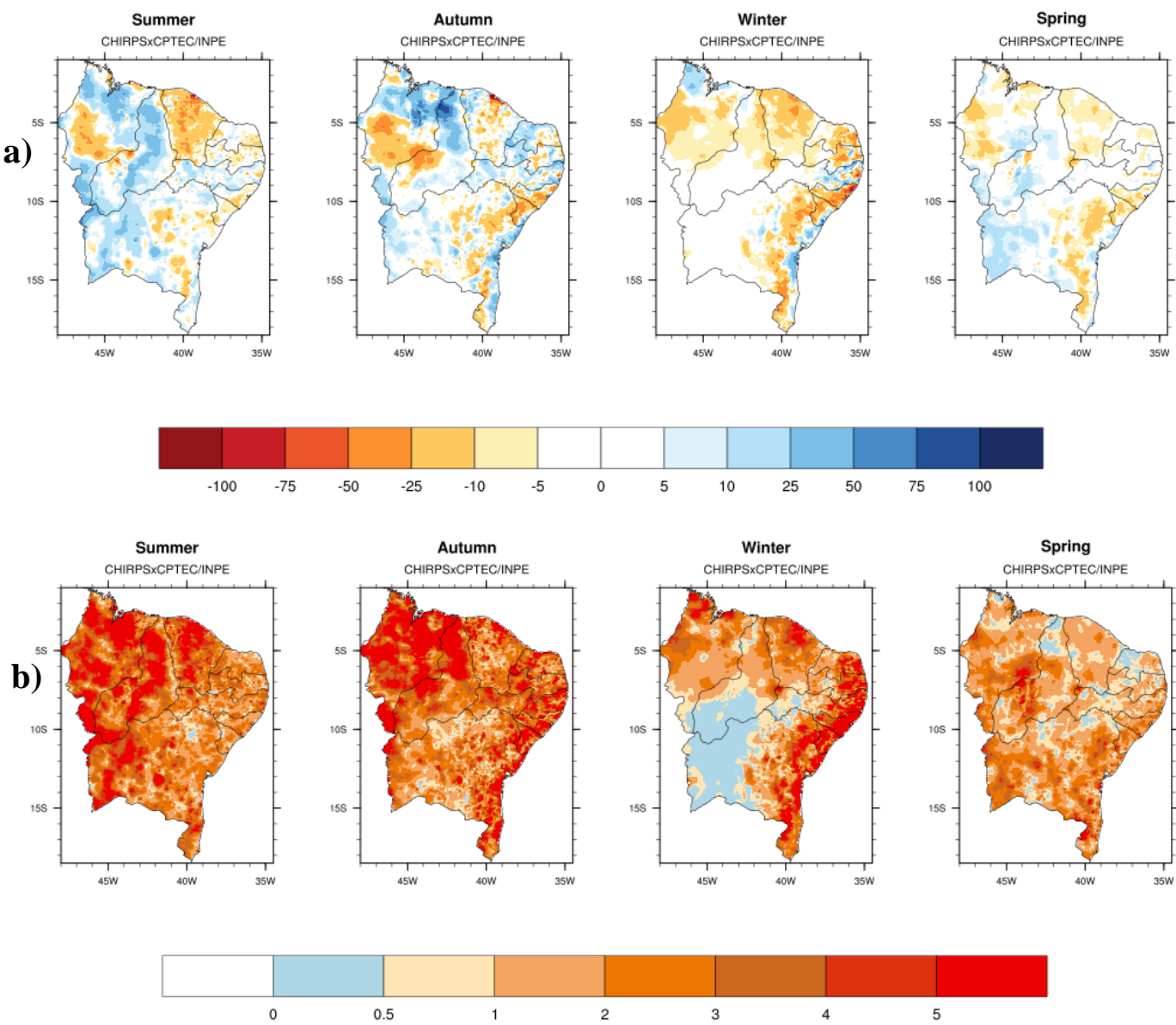

Figura 3 - Viés (a) e RMSE (b) da precipitação sazonal entre o CPTEC/INPE x CHIRPS para as quatro estações do ano, no período de 1999 a 2017.

Na Figura 4 são apresentadas as correlações sazonais entre as anomalias de chuva do CPTEC/INPE e CHIRPS sobre o NEB no período de 1999 a 2017. As correlações de anomalias de precipitação foram calculadas com o intuído de verificar a variação climática. Nota-se uma boa concordância entre as anomalias de chuva observadas e estimadas no período estudado. No verão, outono e 
primavera são verificadas correlações positivas em todo o NEB, evidenciam que os sinais de anomalias seguem a mesma direção, isto é, o CHIRPS reproduz o mesmo sinal de anomalia do dado CPTEC/INPE. Por sua vez, no inverno grande parte do NEB apresenta correlações positivas excetuando uma pequena porção no sul do Piauí e o oeste da Bahia. As regiões observadas com valores negativos de correlação podem estar coerentes, uma vez que, os dados interpolados do CPTEC/INPE podem apresentar erros inerentes à sua interpolação devido a distribuição não homogênea das estações meteorológicas sobre o NEB (Figura 1). Paredes-Trejo et al. (2017), compararam os dados de precipitação do CHIRPS com dados observados de 21 estações de superfície distribuídas pelo o NEB, no período de 1981 a 2013. Os resultados evidenciaram que os dados do CHIRPS se correlacionam bem com as observações em superfície, uma vez que, o $r=0,94$. Todavia, o CHIRPS apresenta erros sistemáticos de superestimativas e subestimativas.

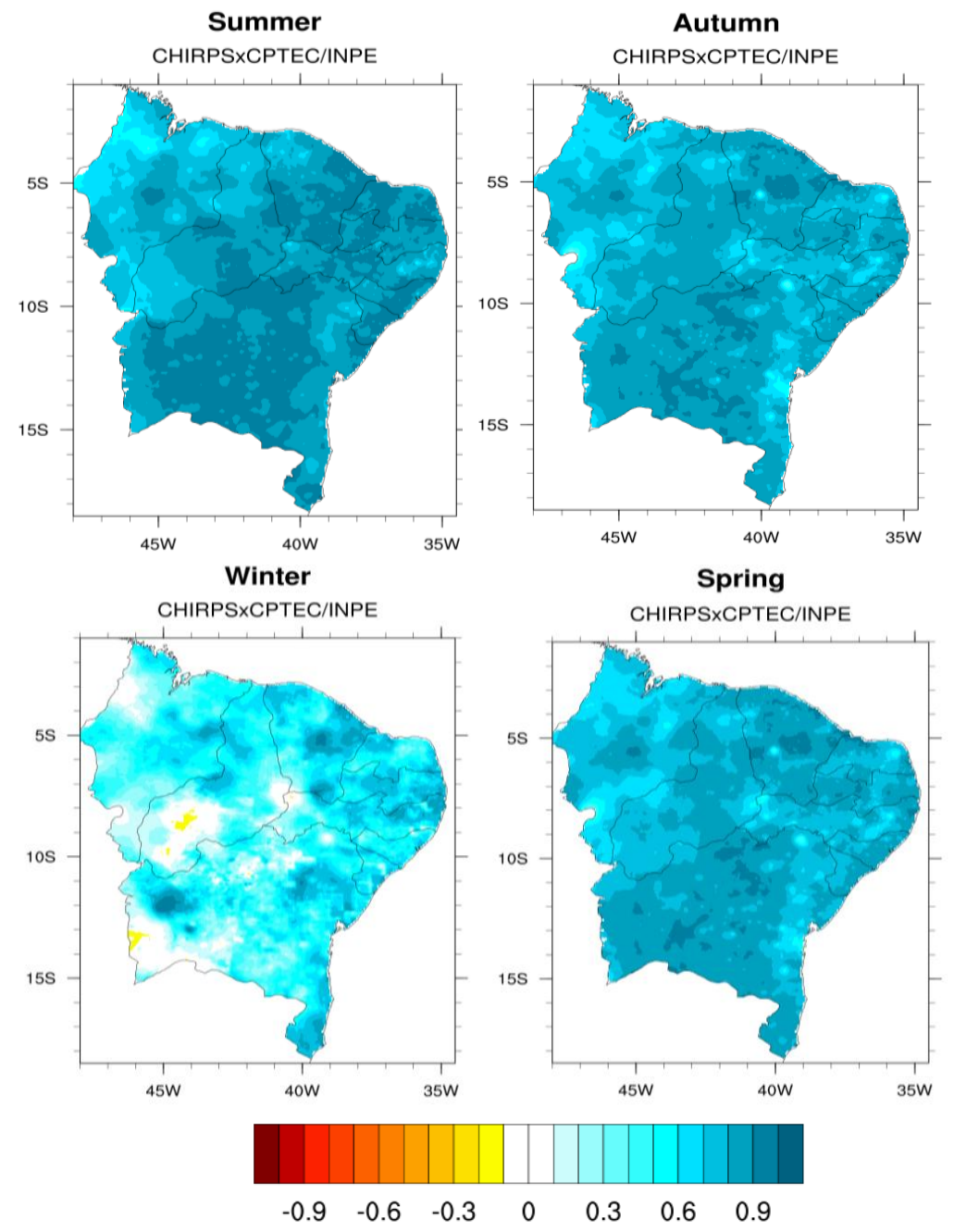

Figura 4 - Correlações sazonais entre as anomalias de chuva do CPTEC/INPE x CHIRPS sobre o NEB no período de 1999 a 2017. 
Diante dos resultados supracitados, verificou-se que o CHIRPS apresenta valores de viés e RMSE pequenos, para as quatros estações do ano, quando comparados com os dados observacionais do CPTEC/INPE. Além disso, o padrão sazonal da precipitação é bem representado pelo CHIRPS no NEB. Desta forma, a série de precipitação do CHIRPS pode ser adicionada a serie de precipitação do CPTEC/INPE, para fins de obtenção de uma séria climatológica de precipitação com alta resolução espacial $(5 \mathrm{Km})$, o que não se dispõe atualmente. Permitindo assim, por exemplo, uma melhor avaliação e/ou quantificação de extremos de precipitação no NEB.

A série de precipitação mensal interpolada para o Nordeste do Brasil, provida pelo CPTEC/INPE compreende o período de 1999 a dezembro de 2017 (19 anos), para a criação da série climatologia foi utilizado 11 anos de dados de precipitação do CHIRPS que compreende o período de 1988 a 1998. A climatologia das precipitações sazonais geradas a partir desta fusão é apresentada na Figura 5. Comparando a amostra climatológica do período de 1999 a 2017 (Figura 2) com a climatologia criada a partir da união dos bancos de dados para o período de 1988 a 2017 (Figura 5) pode-se notar uma grande similaridade entre elas, isto é, a sazonalidade da precipitação continua sendo bem representada pelos dados. Além disso, os três regimes de precipitação no NEB também são representados nesta nova série de precipitação mensal.
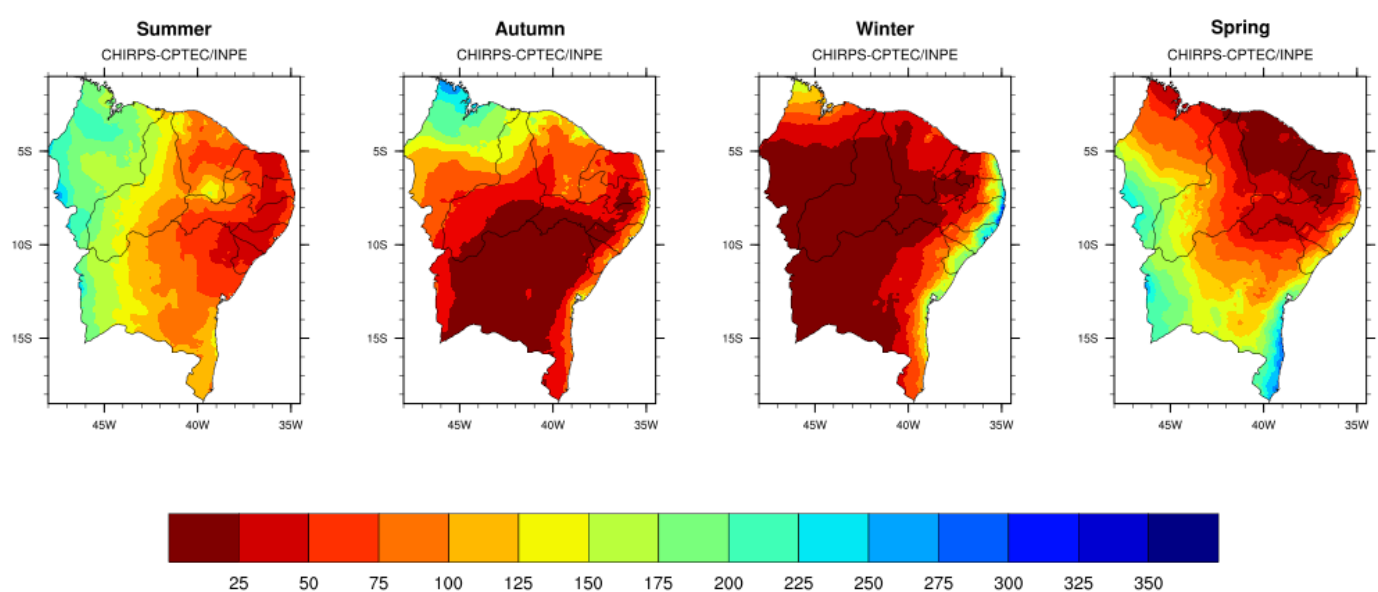

Figura 5 - Climatologia da precipitação sazonal $(\mathrm{mm})$ do CHIRPS-CPTEC/INPE para as quatro estações do ano, no período de 1988 a 2017.

\subsection{APLICAÇÃO DO PRODUTO DE PRECIPITAÇÃO CHIRPS -CPTEC/INPE}

O monitoramento da ocorrência das secas extremas em uma região pode subsidiar estratégias de mitigação dos seus efeitos à população, tanto em escala local como regional. Dessa forma surge a necessidade do desenvolvimento de índices quantificadores de alta resolução espaço-temporal e análises estatísticas, que determinam a intensidade, a duração e a frequência desta anomalia. Um dos índices utilizado é o SPI proposto por McKee et al. (1993). No entanto, uma das exigências para o cálculo do SPI é que a Região em questão apresente uma série de precipitação maior ou igual a 30 anos (HAYES et al. 2000). 
Assim, a Figura 6 apresenta as séries temporais médias do SPI-3, SPI-6 e SPI-12 sobre o NEB a partir da precipitação mensal do CHIRPS-CPTEC/INPE para o período de 1988 a 2017. Note-se nas três escalas do SPI que os anos de 1990, 1992-1993, 1998, 2012, 2015 e 2016 apresentaram mínimos valores dos SPI's, com pico no mês de dezembro de 2015. Recentes estudos mostram que a intensificação da seca ocorrida entre os anos de 2015 e 2016 esteve associada à um forte evento de El Nino ocorrido neste período (RODRIGUES and MCPHADEN, 2014; MARENGO et al., 2017; CUNHA et al., 2018). Verifica-se também que as secas recorrentes ocorridas entre os anos de 2012 a 2017, foram as mais intensas das ultimas décadas. Tal resultado concorda com estudos prévios sobre a avaliação da seca no NEB por meio de SPI, os quais pontuam que a seca ocorrida entre os anos de 2012 a 2017 na região, foi a mais extensa e severa dos últimos 30 anos (BRITO et al., 2017; MARENGO et al., 2017; CUNHA et al., 2018).

Por outro lado, os anos de 1989, 2004 e 2009 apresentaram os maiores valores dos SPI's, representando os eventos chuvosos. Adicionalmente, o máximo valor observado foi em outubro de 2009, ano que teve a influência do fenômeno La Niña, causando chuvas acima da média climatológica principalmente no primeiro semestre do ano. Conforme destacado por Alves et al. (2009), no 2009, também observou-se persistência de anomalias negativas da TSM no Atlântico Norte e anomalias positivas de TSM no Atlântico Sul. Tal gradiente de TSM favoreceu maior atividade convectiva associada à ZCIT sobre a região de águas mais quentes do o normal, resultando em acumulados de precipitação acima da média no norte das Regiões Norte e Nordeste.

Em estudo sobre a importância da variabilidade do sinal entre eventos do ENOS, reportado por Souza e Ambrizzi (2002) e Kayano et al. 2011, sobre a América do Sul mostra que as teleconexões da fase quente/fria do ENSO indicam déficit/excesso de precipitação sobre a Região Amazônica e Nordeste Brasileiro.

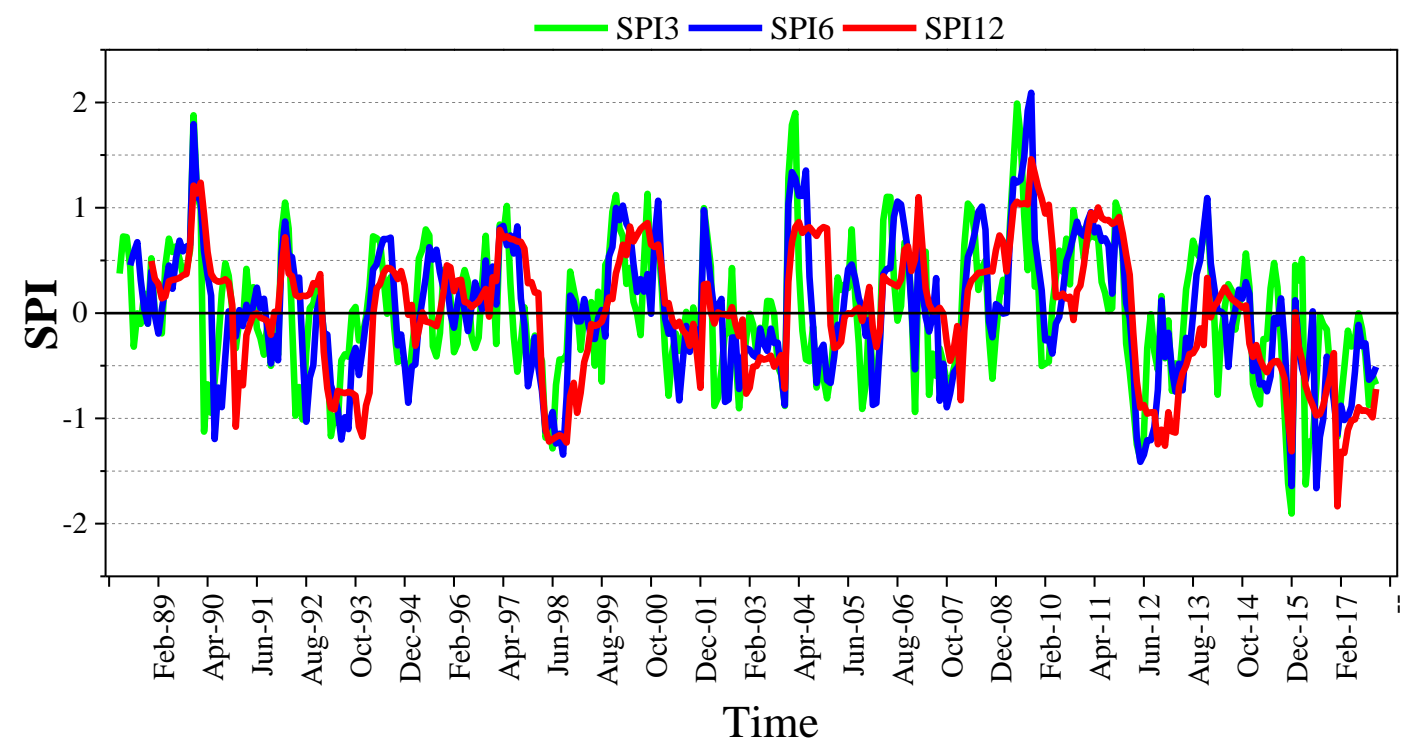

Figura 6 - Série temporal médias do SPI-3, SPI-6 e SPI-12 no NEB. Séries calculadas a partir dos dados de precipitação CHIRPS-CPTEC/INPE no período de 1988 a 2017. 
Uma análise comparativa dos SPI's de dezembro de 2015 (pico do SPI negativo) sobre o NEB obtido com os dados de precipitação do CHIRPSCPTEC/INPE e apenas do CHIRPS considerando a climatologia do período de 1988 a 2017 é apresentada na Figura 7. Na série CHIRPS-CPTEC observa-se valores negativos dos SPI's os quais variam de -1 a -2.5 em grande parte da região. Todavia, no nordeste da região, nos SPI-3 e SPI-6 são observados valores positivos de SPI, com valores em torno de 1 a 1.5 (Figura 7a).

Quando se analisa a série de dados do CHIRPS (Figura 7b), também se verifica em grande parte do NEB valores negativos nos SPI's, excetuando o nordeste da região onde é observado valores positivos, mas em menor intensidade $(0.5$ a 1.0$)$. Esta diferença no campo dos SPI's observados no CHIRPS e CHIPRS-CPTEC pode estar relacionada a densa cobertura estações meteorológicas que o CPTEC/INPE utiliza na assimilação dos seus dados de precipitação, o que resulta em uma informação mais detalhada dos eventos secos e chuvosos no NEB. Entretanto, cabe ressaltar que apesar da diferença em intensidade de ambas as bases de dados, há uma satisfatória representação espacial do SPI em ambas.

a)

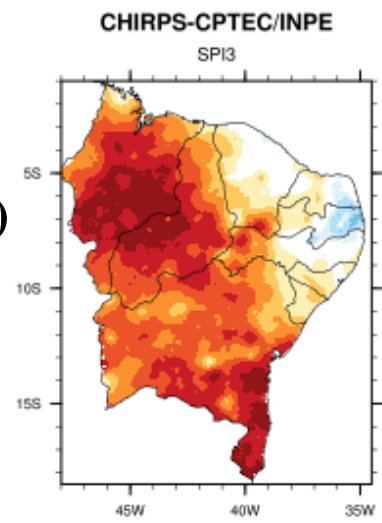

b)

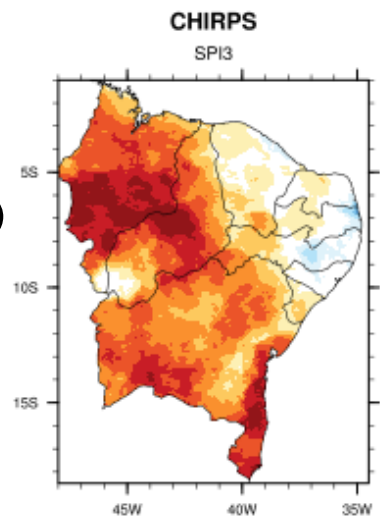

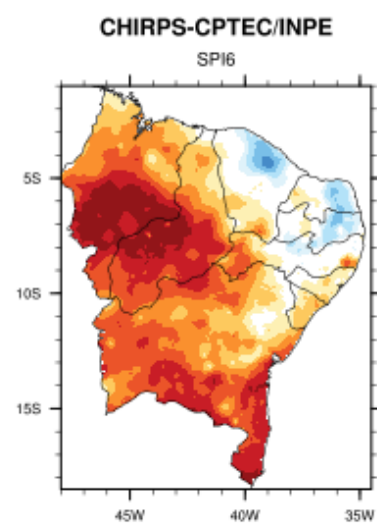

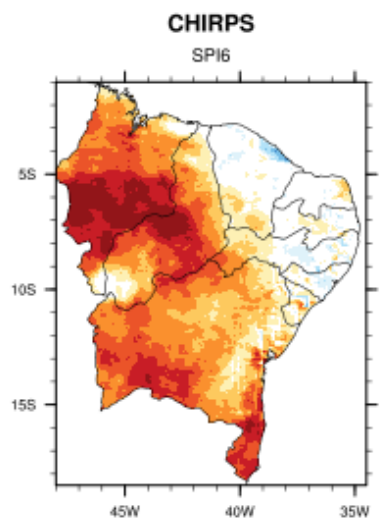

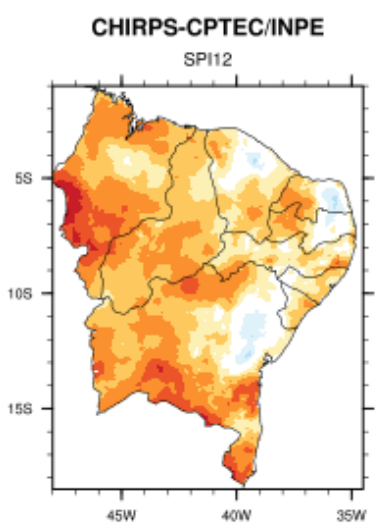

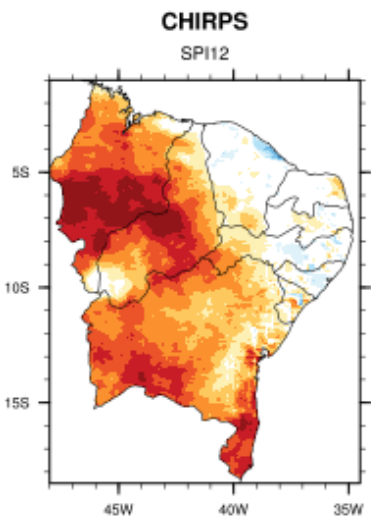

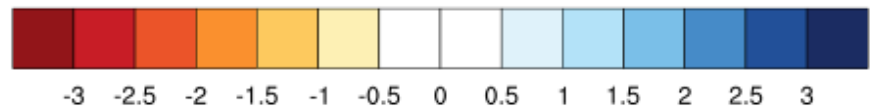

Figura 7 - Série espacial do SPI-3, SPI-6 e SPI-12 de dezembro de 2015 para o NEB obtidas com os dados de precipitação mensal do CHIRPS-CPTEC/INPE(a) e CHIRPS (b), considerando a climatologia de janeiro de 1988 a dezembro de 2017. 
Visando compreender os mecanismos climáticos associados ao evento de seca supracitado, a Figura 8 mostra os campos oceânicos-atmosféricos observados durante o mês de dezembro de 2015. Anomalias positivas de TSM (em torno de $0.8^{\circ} \mathrm{C}$ ) foram observadas em todo o Pacífico e Atlântico Tropical (Figura 8a). Dependendo do tempo de permanência, essas condições oceânicas alteram o padrão de circulação atmosférica zonal e meridional resultando, em geral, em movimentos descentes anômalos do ar sobre as Regiões Norte e Nordeste do Brasil (SOUZA et al. 2005; ANDREOLI e KAYANO, 2007; KAYANO et al. 2011; DOS SANTOS et al. 2017). A seção reta vertical do vento zonal mostra movimentos descendentes anômalos intensos em torno da longitude do NEB $\left(34^{\circ} \mathrm{W}-46^{\circ} \mathrm{W}\right)$ (Figura $\left.8 \mathrm{~b}\right)$. A seção reta vertical do vento meridional também mostra movimentos descendentes intensos sobre o NEB (Figura 8c). Em adição, os valores negativos (positivos) de ômega (velocidade vertical) são indicativos de movimento ascendente (descendentes).

Diante disto, observou-se que dezembro de 2015 foi marcado por anomalias positivas de TSM no Atlântico e Pacífico Tropical, contribuindo para o estabelecimento de uma circulação local meridional e zonal (célula de Hadley e Walker), com movimento ascendente vertical sobre o Atlântico Norte e Pacífico Tropical e movimento vertical descendente (subsidência) no NEB, inibindo assim a formação de nuvens sobre a região em estudo. A combinação das anomalias positivas de TSM observadas no Atlântico Tropical Norte e no Oceano Pacífico Tropical reforça as condições de subsidência na NEB, que são desfavoráveis à ocorrência de precipitação, consequentemente, aos valores negativos de SPI observados neste mês.

(a)
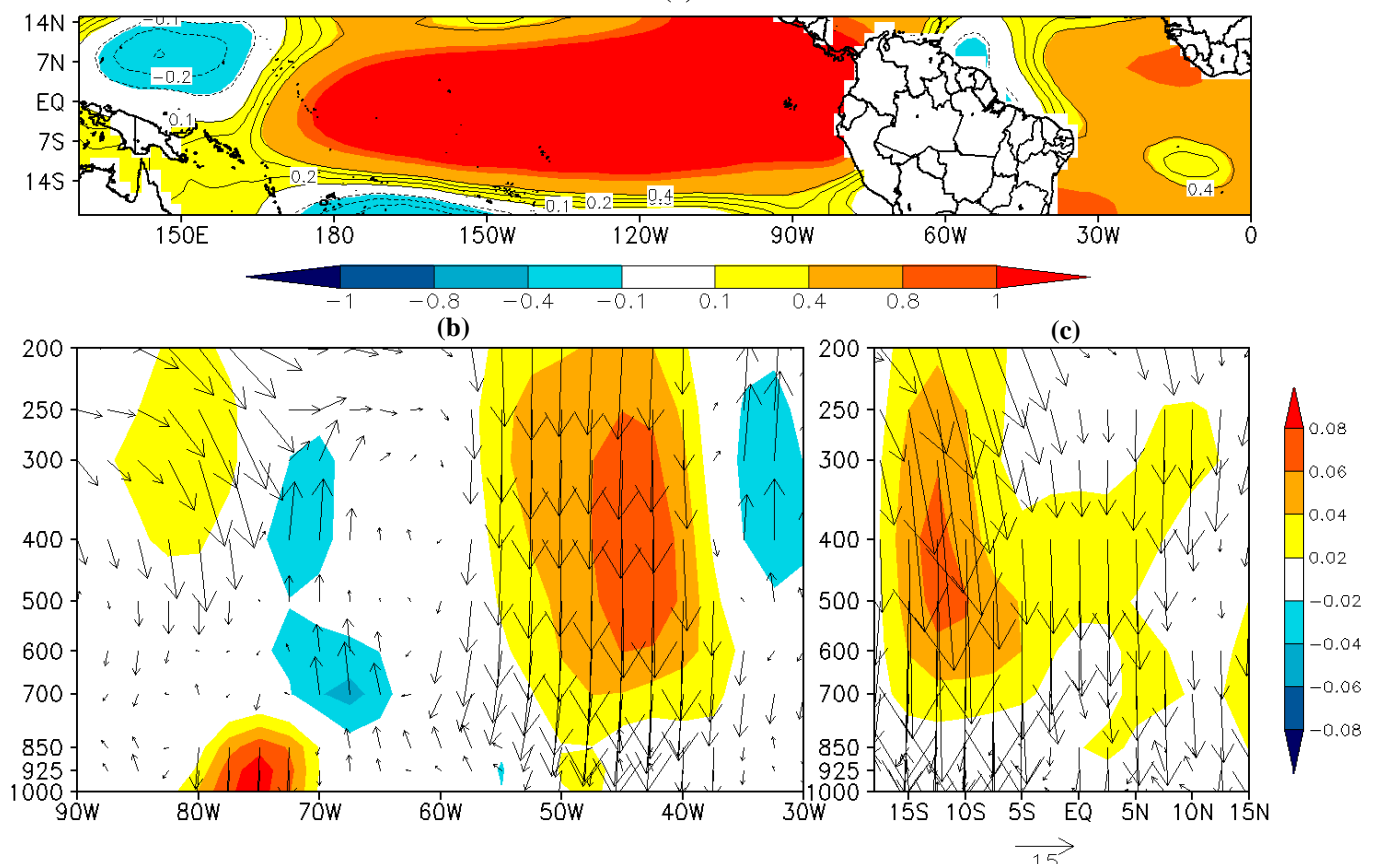

Figura 8 - Anomalias mensais de dezembro de 2015 para: (a) distribuição horizontal da temperatura da superfície do $\operatorname{mar}\left({ }^{\circ} \mathrm{C}\right)$; (b) seção reta vertical zonal (média entre $16^{\circ} \mathrm{S}$ e $\left.3^{\circ} \mathrm{s}\right)$ da componente zonal do vento (m.s-1) e do movimento vertical (50x10-3m.s-1); (c) seção reta vertical meridional (média entre $47^{\circ} \mathrm{W}$ e $38^{\circ} \mathrm{W}$ ) da componente meridional do vento (m.s-1) e do movimento vertical (50x10-3m.s-1). As anomalias foram calculadas considerando a climatologia para o período de 1988-2017 


\section{CONCLUSÃO}

De modo geral, os padrões sazonais de precipitação no NEB foram bem representados com os dados de chuvas proveniente do CPTEC/INPE e do CHIRPS no período de 1999 a 2017, isto é, foi possível identificar os três regimes de precipitação no NEB. Um ao norte nas estações de verão e outono, ao leste no inverno e ao sul na primavera. As análises quantitativas evidenciaram que o CHIRPS apresenta erros sistemáticos de subestimativa (viés negativo) e superestimava (viés positivo) nas quatro estações do ano. Por outro lado, os valores de RMSE não ultrapassam $5 \mathrm{~mm}$ por estação do ano. Desta maneira, os erros sistemáticos do CHIRPS em relação ao CPTEC foram pequenos, o que permitiu a criação de uma nova séria de precipitação mensal que compreende o período de 1988 a 2017. Na criação desta série utilizou-se onze anos de dados de precipitação mensal do CHIRPS (1988 a 1998) e dezenove anos do CPTEC (1999 a 2017). Ao calcular o SPI a partir da série climatológica de precipitação mensal CHIRPS-CPTEC/INPE foi possível observar que a mesma representa de maneira mais detalhada os eventos secos e chuvosos no NEB quando comparados com os eventos secos e chuvosos obtidos apenas com dados do CHIRPS. Isto evidencia, por exemplo, a qualidade desta série climatológica em monitorar eventos extremos de precipitação na região, principalmente os eventos de seca, uma vez que, são recorrentes e persistentes, permitindo assim uma melhor avaliação dos seus impactos na região.

Em adição, o evento de seca observado em 2015 foi causado pelos padrões de circulação atmosférica de grande escala forçados pelas anomalias positivas de TSM no Pacífico Tropical e no Atlântico Tropical Norte e de anomalias negativas de TSM em áreas do Atlântico Tropical Sul, aos quais desfavorecem a formação de nuvens e consequentemente reduziram o volume de chuva sobre a região. Assim, a seca que havia começado no final do ano de 2011, foi intensificada entre os anos de 2015-2016 em razão da ocorrência de El Nino, tornando-se este evento, o mais severo ocorrido nas últimas décadas. Ressalta-se que o início da seca (final de 2011) pode estar associado com as anomalias negativas no Pacífico Central (La Niña) e concomitantemente com anomalias positivas no Atlântico Tropical Norte, o que favoreceu o deslocamento mais ao norte da ZCIT (RODRIGUES e MCPHADEN, 2014). Assim, mesmo com o Pacífico favorável (La Niña), tal condição não foi suficiente para manter as chuvas acima da normalidade.

Por fim, ressalta-se que para o monitoramento dos eventos extremos de precipitação, principalmente em nível municipal, de modo a viabilizar acções de mitigação dos seus efeitos, é necessário que se disponha de um conjunto de precipitação com adequada resolução temporal e espacial. Para isso, a maior contribuição do presente estudo é a criação de um banco de dados climatlógico de precipitação com alta resolução espacial apropriada para a estimativa de diferentes indicadores de seca.

\section{REFERÊNCIAS}

ABBAS, S., NICHOL, J.E., QAMER, F.M., XU, J. Characterisation of drought development through remote sensing: a case study in Central Yunnan, China. Remote Sensing. v.6, n.6, 4998-5018, 2014. 
ALVES, I. M. B., REPELLI, C. A. Rainfall variation in the northern part of the Brazilian Northeast and the El Niño events-Southern Oscillation (ENSO), Revista Brasileira de Agrometeorologia, v. 7, p. 583-592, 1992.

ALVES, L. M.; COELHO, C.A.S.; MELO, A.B.C.; PESQUERO, J.F. Condições Climáticas observadas no Brasil em 2009. Boletim da Sociedade Brasileira de Meteorologia. v. 35, 2009.

ANDREOLI, R. V.; KAYANO, M. T. A importância relativa do atlântico tropical sul e pacífico leste na variabilidade de precipitação do Nordeste do Brasil. Revista Brasileira de Meteorologia, v. 22, p. 63-74, 2007.

ASSIS, J.M.O.; SOUZA, W.M.; SOBRAL, M.C.M. Climate analysis of the rainfall in the lower-middle stretch of the São Francisco river basin based on the rain anomaly index. Revista Brasileira de Ciências Ambientais, v. 2, p. 188-202, 2015.

BRITO, S.S.B., CUNHA, A.P.M.A, CUNNINGHAM, C.C., ALVALÁ, R.C., MARENGO, J.A., ARAUJO, M. Frequency, duration and severity of drought in the Brazilian Semiarid. International Journal of Climatology. v.38, n.2, p.517-529, 2018.

BHUIYAN, C., SINGH, R.P., KOGAN, F.N. Monitoring drought dynamics in the Aravalli region (India) using different indices based on ground and remote sensing data. International Journal of Applied Earth Observation and Geoinformation, v. 8, p. 289-302, 2016.

COSTA, M. S. Vórtice Ciclônico Em Altos Níveis Associado À Corrente De Jato No Nordeste Brasileiro Nos Anos De 1998-2007. 2010. 113 F. Dissertação (Mestrado Em Meteorologia) - Universidade Federal De Alagoas, Maceió - Al. 2010.

COSTA, J.A. O fenômeno El Niño e as secas no Nordeste do Brasil. Revista Científica do IFAL, v.1, n.4. 2012.

CAVALCANTE, I.F.A.; FERREIRA, N.J.; SILVA DIAS, M.A.F.; JUSTI, M.G.A. Tempo e clima no Brasil. São Paulo: Oficina de Textos, 2009.

CPTEC/INPE - Centro de Previsão de Tempo e Estudos Climáticos/ Instituto Espacial de Pesquisas Espaciais - Dados Observacionais. Disponível em: http://bancodedados.cptec.inpe.br/. Acessado em janeiro de 2018.

COUTINHO, M. D. L; GAN, M. A.; RAO, V. B. Método objetivo de identificação dos Vórtices Ciclônicos de Altos Níveis na região Tropical Sul: validação. Revista Brasileira de Meteorologia, v. 25, p. 311-323, 2010.

CUNHA, A.P.M.A., TOMASELLA J, RIBEIRO-NETO GG, et al. Changes in the spatial-temporal patterns of droughts in the Brazilian Northeast. Atmospheric Science Letters. v.19, n.10, 2018.

DOS SANTOS, S. R. Q.; BRAGA, C. C.; SANSIGOLO, C. A.; DE ARAUJO TIBURTINO NEVES, T. T. ; DOS SANTOS, A. P. P. 2017. Droughts in the Amazon: Identification, Characterization and Dynamical Mechanisms Associated. American Journal of Climate Change, v. 06, p. 425-442, 2017.

EAKIN, H.C.; LEMOS, M.C.; NELSON, D.R. Differentiating capacities as a means to sustainable climate change adaptation, Global Environmental Change, Volume 27, Pages 1-8, 2014. 
IBGE, Instituto Brasileiro de Geografia e estatística. Censo Agropecuário, Rio de Janeiro, 2006. Disponível em: https://www.ibge.gov.br. Acesso em junho de 2017.

FASULLO, J. A. Mechanism for land-ocean contrasts in global monsoon trends in a warming climate. Climate Dynamics. v. 39, p. 1137-1147, 2012.

FUNK, C. C. et al. A quasi-global precipitation time series for drought monitoring. US Geological Survey Data Series, v. 832, n. 4, 2014.

FERREIRA, P. S. et al. Variabilidade Espaço-Temporal das Tendências de Precipitação na Mesorregião Sul Cearense e sua Relação com as Anomalias de TSM. Revista Brasileira de Meteorologia, São Paulo, v. 33, n. 1, p. 141-152, 2018.

GAN M. A.; KOUSKY, V.E. Vórtices ciclônicos da alta troposfera no oceano Atlântico Sul. Revista Brasileira de Meteorologia, v. 1, 19-28, 1986.

GIBBS, W.J., MAHER, J.V., 1967. Rainfall Deciles as Drought Indicators. Bureau of Meteorology Bulletin No. 48. Commonwealth of Australia, Melbourne.

GUTTMAN, N. B. Comparing the Palmer drought index and the standardized

precipitation index. Journal of the American Water Resources Association. v.34, p. 113-121, 1998.

HAYES, M. J.; SVOBODA, M.D.; WILHITE, D.A.; VANYARKHO, O.V. Monitoring the 1996 drought using the Standardized Precipitation Index. Bulletin of the American Meteorological Society. v. 80, n.3, p.429-438, 1999.

HAYES, M. J. Revisiting the SPI: clarifying the process. 2000.

HOSSEINI-MOGHARI, S. M., Araghinejad, S. Monthly and seasonal drought forecasting using statistical neural networks. Environmental Earth Sciences 74, 397-412, 2015.

HASTENRATH, S., HELLER, L. Dynamics of climatic hazards in Northeast Brazil. Quartely Journal of the Royal Meterological Society, v.103, n.435, p77-92, 1977.

HASTENRATH, S. Interannual variability and annual cycle: mechanisms of circulation and climate in the tropical Atlantic. Monthly Weather Review. v.112, p.1097-1107, 1984.

KOUSKY, V. E. Frontal influences on Northeast Brazil. Montly Weather Review. 107, 1140-1153.1979, 1979.

KAYANO, M. T; ANDREOLI, R. V.; SOUZA, R.A.F. 2011. Evolving anomalous SST patterns leading to ENSO extremes:relations between the tropical Pacific and Atlantic Oceans and the influence on the South American rainfall. International Journal of Climatology, v. 31, p. 1119-1134, 2011.

KEYANTASH, J., DRACUP, J.A., 2004. An aggregate drought index: assessing drought severity based on fluctuations in the hydrologic cycle and surface water storage. Water Resources Research. 40, W09304.

KOGAN, F.N. Remote sensing of weather impacts on vegetation in nonhomogeneous areas. International Journal of Remote Sensing. v.11, n.8, p.1405-1419, 1990. 
KOGAN, F.N. World droughts in the new millennium from AVHRR-based Vegetation Health Indices. Eos Transactions American Geophysical Union. v.83, n.48, p.562-563, 2002.

LIMBERGER, L.; SILVA, M. E. S. Precipitação observada na Amazônia brasileira: comparação entre os dados das redes convencionais e dados da Reanálise I do NCEP/NCAR, CRU e GPCC. Revista Brasileira de Climatologia, v. 22, p. 20-37, 2018.

LINDOSO, D.; ROCHA, J. D.; DERBOTOLI, N. PARENTE, I. I. C; EIRÓ, F. BURSZTYN, M.; RODRIGUES-FILHO. Climate Change and Vulnerability to drought in the Semiarid: the case of smallholder farmers in the Brazilian northeast. In: Seroa da Motta, R.; Hargrave, J.; Luedemann, G.; Gutierrez, M. B. S. (Eds.). Climate change in Brazil: economic, social and regulatory aspects. Brasilia: Ipea, p. 235-256, 2011.

MAGALHÃES, A. R.; GLANTZ, M. H., 1992: Socioeconomic impacts of climate variations and policy responces in Brazil, United Nations Environment Program (UNEP), Secretariat for Planning and Coordination State of Ceara (SEPLAN), Esquel Brasil Foundation, 155 pp.

MOLION, L.C.B.; BERNARDO, S.O. Uma revisão da dinâmica das chuvas no Nordeste Brasileiro. Revista Brasileira de Meteorologia, v.17, n.1, p. 1-10, 2002.

MOURA, A.D. AND SHUKLA, J. On the Dynamics of Droughts in Northeast Brazil: Observations, Theory and Numerical Experiments with a General Circulation Model. Journal of the Atmospheric Sciences. v.38, p.2653-2675, 1981.

MARENGO, J. A. Vulnerabilidade, impactos e adaptação à mudança do clima no semi-árido do Brasil, Parcerias Estratégicas, v. 27, p. 149-175, 2008.

MARENGO. J. A. Mudanças Climáticas e eventos extremos no Brasil. Fundação Brasileira para o Desenvolvimento sustentável. Brasília: MMA, 2012. Disponível em: http://www.fbds.org.br/cop15/FBDS_MudancasClimaticas.pdf.

MARENGO, J.A., Alves, L.M., Alvala, R.C., Cunha, A.P., Brito, S.S., Moraes, O.L.L. Climatic characteristics of the 2010-2016 drought in the semiarid Northeast Brazil region, Anais da Academia Brasileira de Ciências. v.90, n.2, pp.1973-1985, 2018.

MATHERON, G. Le krigeage universel. v.1. Cahiers du Centre de Morphologie Mathematique, Ecole des Mines de Paris, Fontainebleau, 83 p, 1969.

MCKEE, T.B., DOESKEN, N. J., KLEIST, J. Therelationnships of drought frequency and duration to time scales. 8th Conference on Applied Climatology, Anaheim, CA. Preprints. Bull. American Meteorological Society, 233-236, 1993.

MENDONÇA, F.; DANNI-OLIVEIRA, I. M. Climatologia: noções básicas e climas do Brasil. São Paulo: Oficina de Textos, 206p. 2007.

MACHADO, C.C.C.; NÓBREGA, R.S.; OLIVEIRA, T.H.; ALVES, K.M.A. Distúrbio Ondulatório de Leste como condicionante a eventos extremos de precipitação em Pernambuco. Revista Brasileira de Climatologia. v.11, n.8, p.146-188, 2012.

NOBRE, P. MELO, A. B. C. Variabilidade climática intrasazonal sobre o Nordeste do Brasil em 1998-2000. Revista Climálise. Publicação on line. 2001. 
NÓBREGA, R.S.; SANTIAGO, G.A.C.F. Tendência de temperatura na superfície do mar nos oceanos atlântico e pacífico e variabilidade de precipitação em Pernambuco. Mercator, v. 13, n. 1, p. 107-118, 2014.

PALMER, W.C., 1965. Meteorological Drought. Research Paper No. 45. U.S. Department of Commerce Weather Bureau, Washington, DC.

PAREDES-TREJO, Franklin J.; BARBOSA, H. A.; KUMAR, TV Lakshmi. Validating CHIRPS-based satellite precipitation estimates in Northeast Brazil. Journal of arid environments, v. 139, p. 26-40, 2017.

REBOITA, M. S.; GAN, M. A.; ROCHA, R. P.; AMBRIZZI, T. Regimes de precipitação na América do Sul: uma revisão bibliográfica. Revista Brasileira de Meteorologia, 25, 185-204, 2010.

RODRIGUES, R.R. MCPHADEN, M.J. Why did the 2011-2012 La Niña cause a severe drought in the Brazilian northeast.Geophysical Research Letters, 4, 1012-1018, 2014.

SANTOS, S. R. Q.; BRAGA, C. C.; SANSIGOLO, C. A.; SANTOS, A. P. P. Determinação de Regiões Homogêneas do Índice de Precipitação Normalizada (SPI) na Amazônia Oriental. Revista Brasileira de Meteorologia, v. 32, p. 111122, 2017.

SANTOS, A. P. P. et al. Precipitação na Cidade de Salvador: Variabilidade Temporal e Classificação em Quantis. Revista Brasileira de Meteorologia, v. 31, p. 1-14, 2016a.

SANTOS, A. P. P. et al . Dynamical mechanisms associated to the occurrence of an extreme climatic event of precipitation in the city of Salvador-BA. Revista Brasileira de Geografia Física, v. 9, p. 2196-2212, 2016b.

SHAFER, B.A., DEZMAN, L.E. Development of a Surface Water Supply Index (SWSI) to assess the severity of drought conditions in snowpack runoff areas. In: Proceedings of the Western Snow Conference, Fort Collins, CO, pp. 164-175, 1982.

SOUZA, S.S., TOMASELLA, J., GRACIA, M.G., MENEZES, P.C.P., AMORIN, M.C., PINTO, C.A.M.,2001. O Programa de Monitoramento Climático em Tempo Real na área de atuacão da SUDENE: PROCLIMA. Bol. Soc. Bras. Meteor. 25, 15-24.

SOUZA, E. B.; AMBRIZZI, T. ENSO impacts on the South American rainfall during 1980s: Hadley and Walker circulation. Atmosfera, n.15, p.105-120, 2002.

SOUZA, E.B.; KAYANO, M.T. ; AMBRIZZI, T. Intraseasonal and submonthly variability over the Eastern Amazon and Northeast Brazil during the autumn rainy season. Theoretical and Applied Climatology, v. 81, p. 177-191, 2005.

SUDENE, Superintendência do Desenvolvimento do Nordeste. Delimitação do Semiárido. Disponível em: http://www.sudene.gov.br/planejamentoregional/delimitacao-do-semiarido. Acesso em abril de 2018.

UVO, C. R. B.; NOBRE, C. A. Zona de convergência intertropical (ZCIT) e a precipitação no Norte do Nordeste do Brasil. Boletim de Monitoramento e Análise Climática, v.4, p. 34-40, 1989. 
WILKS, D. S. Statistical Methods in the Atmospheric. Sciences Academic World Meteorological Organization (WMO). 2009. Inter-Regional Workshop in Indices and Early Warning Systems for Drought. 2006.

WMO. World Meteorological Organization: Standardized Index User Guide, (WMO-No. 1090), World Meteorological Organization, Geneva, Switzerland. 2009. Disponivel em: http://www.droughtmanagement.info/literature/WMO_standardized_precipitatio n_index_user_guide_en_2012.pdf. 